\title{
FORMAÇÃO CONTEXTUALIZADA E CRIATIVA DE PROFESSORES DE MATEMÁTICA EM UMA ATIVIDADE DIDÁTICA NA DISCIPLINA DE FÍSICA I
}

\author{
CONTEXTUALIZED AND CREATIVE TRAINING OF MATHEMATICS \\ TEACHERS IN A DIDACTIC ACTIVITY IN THE PHYSICS DISCIPLINE I
}

\author{
Margareth S. B. de Oliveira ${ }^{1}$; Ma da Glória F. N. Albino²; Amadeu Albino Jr. ${ }^{3}$
}

\begin{abstract}
RESUMO
A docência atual exige a excelência dos profissionais educadores. Isso requer uma formação na qual, tão importante quanto o que se ensina, é como se ensina. Sendo assim, a formação dos licenciandos é responsabilidade das diferentes disciplinas que integram o currículo de cada curso. O professor formador é responsável por organizar atividades nas quais sejam apresentadas tarefas com potencial para desenvolver habilidades docentes. Configura-se dessa forma, a proposição do presente trabalho que é descrever o desenvolvimento de uma atividade da disciplina Física I, na licenciatura de Matemática - a elaboração de um plano de aula diferenciada contextualizado pela Cinemática ou Dinâmica. A metodologia efetivou-se em perspectiva dialógica, compartilhada e reflexiva no intento de ampliar a capacidade produtiva, contextualizada e criativa dos futuros professores. O percurso foi desenvolvido em quatro etapas consecutivas: motivação, atividades teóricas com a modelagem, produção de um plano de aula e reflexão e reorganização dos planos. Ao final da reflexão e do replanejamento, foi perceptível que os futuros professores (a partir de suas explicitações) entenderam a necessidade de saberes que possibilitem novas formas de ensinar e aprender. Os saberes a ensinar de Matemática, por fornecerem ferramentas para descrever fenômenos; os de Física, por apresentar e discutirem situações; e, dialeticamente, nortearem a utilização de ferramentas matemáticas. É indubitável que a satisfação das demandas surgidas durante o processo não foi total. Isso, longe de ser visto de forma negativa, pode ser motivação para a concepção identitária dos futuros professores como agentes ativos de seu processo de formação e desenvolvimento.
\end{abstract}

Palavras-Chave: formação docente, licenciatura em matemática, contextualização, conhecimentos físicos.

\begin{abstract}
Today's teaching demands the excellence of professional educators. And this requires a formation where as important as what is taught, is how it is taught. So, the training of graduates is the responsibility of the different disciplines that integrate the curriculum of each course. The teacher trainer is responsible for organizing activities in which tasks with the potential to develop teaching skills are presented. Thus, the proposition of the present work is to describe the development of an activity of Physics I, in the mathematics degree - the elaboration of a differentiated lesson plan contextualized by Kinematics or Dynamics. The methodology was carried out in a dialogical, shared and reflexive perspective in the attempt to expand the productive, contextual and creative capacity of the future teachers. The course was developed in four consecutive stages: motivation; theoretical activities with modeling; production of a lesson plan and reflection and reorganization of plans. At the end of the reflection and replanning, it was perceptible that the future teachers (from their explanations) understood the need for knowledge to enable new ways of teaching and learning. The knowledge to teach of Mathematics, for providing tools to describe phenomena; those of
\end{abstract}

\footnotetext{
${ }^{1}$ Mestre, IFRN/CNAT e EPCAR, magdeoliveira@gmail.com

${ }^{2}$ Doutora, IFRN/CNAT, gloria.albino@ifrn.edu.br

${ }_{3}^{3}$ Mestre, IFRN/CNAT, amadeualbinojunior@gmail.com
} 
Physics, for presenting and discussing situations; and, dialectically, guide the use of mathematical tools. Undoubtedly, the satisfaction of the demands made during the proceedings was not complete. This, far from being viewed in a negative way, can be a motivation for the identitary conception of future teachers as active agents of their formation and development process.

Keywords: initial formation, degree in mathematics, contextualization, planning.

\section{INTRODUÇÃO}

No processo educativo docente, a formação integral (pessoal e profissional) dos licenciandos é responsabilidade das diferentes disciplinas que integram o currículo de cada curso. Fazer da formação inicial profissional o lugar de aprendizagem é estabelecer como objetivo, a criação de um ambiente onde se partilha e constrói significados no qual os sujeitos, ao interagirem enquanto assimilam conteúdos, estabelecem seus motivos, partilham significados, dão sentido a sua formação. Nesse sentido, uma das possíveis vias para conseguir lograr a formação de professores de Matemática que sejam preparados para a realização de tarefas contextualizadas e criativas é a proposição de atividades que, em um primeiro plano, os preparem, de forma teórica (conceitos e procedimentos exigidos pela Matemática), mas devem também ensinar-lhes a coordenação de ações educativas para que possam assimilar um modelo de atuação profissional. A docência atual, devido às exigências e contradições encontradas na escola, exige a excelência dos profissionais educadores. Essa excelência requer uma formação de conhecimentos para a execução de um processo pedagógico onde tão importante quanto o que se ensina, é como se ensina. E assim, o professor formador é responsável por construir e organizar atividades nas quais sejam apresentadas tarefas com potencial para desenvolver habilidades docentes, ou seja, com intencionalidade didática de engajar os saberes matemáticos e pedagógicos de forma contextualizada no processo de ensino e aprendizagem.

A dificuldade na interpretação da linguagem matemática, a desvinculação de sua produção da realidade e a mecanização nas resoluções de problemas, impossibilitam a capacidade criativa e questionadora, sejam dos licenciandos ou de seus futuros alunos, no processo ensino-aprendizagem. Essa conscientização, por parte dos licenciandos, da falta de habilidade para identificar e aplicar um recurso matemático que já estudaram na descrição de um fenômeno físico e conectar o resultado numérico com o fenômeno, justifica a preocupação em relação a contextualização e generalização, já que muitos fenômenos físicos só podem ser compreendidos por meio da linguagem matemática e essa, muitas vezes, não é transmitida com clareza e contextualizada, permanecendo a prática mecanicista na qual "as atividades escolares acabam por se restringir às aplicações de formalismos matemáticos e aos exercícios numéricos 
extraídos das teorias” (PIETROCOLA, 2002, p. 92).

Nesse sentido, a disciplina de Física I (oferecida no quarto período do curso de Licenciatura em Matemática do IFRN/CNAT) pode se configurar como uma boa oportunidade de desenvolver, de forma contextualizada e criativa, um planejamento de aula diferenciada, ou seja, uma aula fora dos parâmetros tradicionais mecanicistas. Numa proposição em que o conhecimento matemático seja o objeto essencial para a interação pedagógica entre o professor (licenciando) e a turma (para qual será produzida o planejamento).

Configura-se assim, a proposição do presente trabalho que é descrever o desenvolvimento de uma atividade propositiva dos alunos da disciplina Física I na elaboração de um planejamento para uma aula diferenciada na abordagem de um conteúdo matemático contextualizado pela Cinemática ou Dinâmica.

\section{Os conhecimentos profissionais e a formação docente}

Os conhecimentos necessários à profissão docente, ocupam lugar de destaque na lista que apresenta as reivindicações para o status profissional dos professores. Segundo Puentes, Aquino e Quilici Neto (2009), os teóricos, apoiados na premissa de que existe um "Knowledge base" para o ensino, afirmam que é possível convalidar esse corpus de saberes com a intenção de melhorar a formação dos professores. Para Shulman (1986) a base de conhecimento alude à existência de um repertório profissional, ou seja, um conjunto de saberes profissionais, que inclui categorias de conhecimento que estão submetidas à compreensão necessária para que o professor possa promover a aprendizagem.

Na visão dita tradicional, que ainda pode ser reconhecida em muitos professores da área, basta que o professor seja um especialista, um conhecedor profundo da Matemática para que ele possa ensinar. Essa visão tem contribuído para que o futuro professor se identifique com a imagem de mero repetidor de um saber alheio. Mas, que saber é esse? Há uma única Matemática (igual para bacharéis e licenciandos)? Sem entrar no mérito da questão, podemos dizer que os saberes profissionais docentes, segundo Valente (2017) apresentam duas naturezas: o saber a ensinar, relacionado a campos específicos do conhecimento e que constitui objeto de trabalho do professor; e o saber para ensinar, fruto de elaboração histórica do ofício docente, ferramental acionado para melhor realizar o ofício de ensinar os saberes que a sociedade atribui à escola como sua função institucional.

No contexto da formação docente, segundo Cardim e Grano (2011) percebe-se como sendo relevante possibilitar experiências vivenciais durante a formação inicial, que deem condições para uma significação e composição de bases pedagógicas, contribuindo para a 
constituição profissional do educador, sem desconsiderar a importância da prática na mobilização/produção do saber docente, que se relaciona as dinâmicas e intervenções dos atores envolvidos com o processo de ensino-aprendizagem.

Assim sendo, na atual sociedade da comunicação e conhecimento, é cada vez mais necessária, a percepção da relevância do professor formador como um orientador no processo de desenvolvimento dos futuros professores como produtores de saberes (os saberes a ensinar e os saberes para ensinar). E, nesse sentido, o saber não é uma substância ou um conteúdo fechado em si mesmo; ele se manifesta através de relações complexas entre o professor e os aprendentes. Diz Tardif (2002, p. 17): “[...] as relações dos professores com os saberes nunca são relações estritamente cognitivas: são relações mediadas pelo trabalho que lhes fornece princípios para enfrentar e solucionar situações cotidianas".

Assim posto, é preciso que os licenciandos possam ser preparados, e se preparem, de forma contínua, para exercitar e ampliar sua cultura Matemática e docente no sentido de trabalhar situações concretas, por mais modestas que sejam as condições, objetivando que o saber a ser ensinado motive o prazer em conquistar o conhecimento.

\section{O conhecimento físico para professores de Matemática}

Entendendo a Matemática como uma linguagem, percebemos que a Ciência vale-se dela como forma de expressar seu pensamento, possibilitando argumentação de ideias sobre a natureza, não apenas como um instrumento de comunicação, mas também “como expressão do nosso próprio pensamento" (PIETROCOLA, 2002). O formalismo matemático tem se mostrado a linguagem mais apropriada e pertinente para esse propósito (BATISTA e MOZOLEVSKI, 2010). Contudo, muitas vezes existe a falta de compreensão dos conhecimentos matemáticos por parte dos alunos. Não obstante, a questão reside na forma como a Matemática é ensinada no contexto da Física (PIETROCOLA, 2002). Há a necessidade do abandono do operativismo mecânico - no qual o aluno aprende técnicas aritméticas e depois realiza alguns cálculos, não constatam sua relação com algo prático - e da maneira como ocorre o processo de transferência de informação - linear e hierárquico, no qual aluno é aquele que não sabe e o professor é o possuidor do conhecimento. Por isso, a importância de ensinar Matemática de uma forma contextualizada, integrada e relacionada a outros conhecimentos, mobilizando conceitos entre contextos, permitindo destarte a capacitação dos licenciandos para compreender e interpretar situações, apropriando-se de linguagens específicas, de forma a argumentar, analisar e avaliar as ações necessárias à sua formação acadêmica. Contudo, existe a dificuldade de interpretação e apropriação de conceitos de outras áreas do conhecimento, como os da Física, de forma a 
serem usados como ferramentas para abordagem do conhecimento matemático. A possibilidade de trabalhar conceitos da disciplina de Matemática utilizando, não o ensino tradicional mecanicista e autoritário -, mas levando em consideração outras propostas metodológicas como, por exemplo, a posse da descrição de fenômenos físicos para pleitear conceitos matemáticos, prepara o futuro docente em Matemática no desempenho do seu papel de difusor do conhecimento contextualizado e, consequentemente, possibilita seu futuro aluno a participar ativamente do processo de construção deste conhecimento.

Todavia, para que o panorama se modifique, faz-se necessário o comprometimento, já que, tanto o professor formador como o licenciando, são responsáveis pela qualidade do ensino; o professor formador, desempenhando um trabalho docente de qualidade, e os licenciandos comprometidos em querer aprender (FELICETTI e MOROSINI, 2010).

\section{METODOLOGIA}

A metodologia utilizada efetivou-se em perspectiva dialógica, compartilhada e reflexiva entre professor formador e licenciandos no intento de ampliar a capacidade produtiva, contextualizada e criativa dos estudantes da licenciatura em Matemática, o que proporcionou ao formador criar caminhos e interfaces de ação e atuação em sala de aula, enquanto docente da disciplina Física I em um curso de Matemática, além de adotar um compromisso interativo e integrativo, viabilizando a construção de conhecimentos teóricos e práticos. E assim, o objetivo se concretiza com a descrição da atividade propositiva.

O percurso metodológico se desenvolveu 4 (quatro) etapas, sendo elas:

- Motivação - Discussão (a desmistificação dos conteúdos de Física como sendo difíceis e não necessários na formação dos professores de Matemática);

- Atividades teóricas com a modelagem de conceitos físicos utilizando a linguagem matemática (os fenômenos físicos tornam-se objetos de estudo descritos por modelos matemáticos);

- Proposição da produção de um plano de aula na perspectiva do ensino ativo utilizando os conceitos relativos a Cinemática ou Dinâmica (buscou-se investigar os saberes necessários ao professor de Matemática, observados na prática por esses licenciandos, que configurarão a forma de como contextualizar os conceitos matemáticos, a partir dos conceitos físicos discutidos e estudados em sala de aula, distanciando de modelos tradicionais de ensino); 
- Reflexão e reorganização dos planos de aula produzidos (possibilitando a análise e avaliação de suas possíveis atuações, identificando pontos fracos e fortes, refletindo, assim, sobre a melhoria das ações a serem desenvolvidas - induzir o futuro professor a pensar sobre sua prática em sala de aula).

\section{RESULTADOS E DISCUSSÃO}

A apropriação da metodologia dialógica e compartilhada levou a atividade ao plano de reflexão em relação aos saberes a serem formados e ao diálogo estimulando à participação e indagação por parte dos licenciandos, tornando-os agentes ativos no processo da construção do conhecimento.

Na primeira etapa - Motivação - Discussões relativas a conceitos e preconceitos - Essa etapa foi importante para fazer a condução de toda a atividade. Nela, os futuros professores, sob a orientação do formador, puderam compartilhar seus saberes, suas motivações ou dificuldades para a formação de conceitos físicos (o saber para ensinar e o saber a ensinar). As discussões levaram a construção de alguns paradigmas como compreender o que se pretende ensinar; e ter um conhecimento mais amplo e generalizado do que se almeja comunicar.

A etapa seguinte - Atividades teóricas com modelagem de conceitos físicos - Essa fase se concretizou na apreciação, inicial, dos conteúdos matemáticos a serem aprendidos e como serem ensinados a partir de contextualização, uma situação real. Nessa contextualização, a realidade é modelada por conceitos físicos e comunicada em linguagem matemática.

A terceira etapa - Produção de um plano de aula - A classe foi dividida em grupos compostos por 3 (três) ou 2 (dois) integrantes, vale ressaltar que 3 (três) licenciandos desenvolveram o plano de aula individualmente. Os estudantes puderam planejar, seja em grupo ou individualmente, e buscar orientações com o professor formador. A proposta da atividade era de realizar, de maneira simplificada e criativa, um plano para uma aula diferenciada de matemática, contextualizada em conceitos físicos, com os temas discutidos durante a etapa 2 (modelagem) - os conceitos poderiam ser relativos a Cinemática ou Dinâmica.

Durante essa fase ficou nítida a dificuldade encontrada pela maioria na escolha de um conteúdo matemático que pudesse ser desenvolvido em uma aula diferenciada com um contexto físico. Os temas escolhidos por eles para o planejamento foram corretos, mas não destacaram as ferramentas matemáticas a serem utilizadas em suas abordagens. Grande parte desenvolveu uma aula de Física num ambiente diferenciado como, por exemplo, a pista de atletismo do Instituto, sem destacar qual o conteúdo matemático a ser trabalhado. A Matemática, em todos os planos apresentados, foi utilizada como ferramenta para ensinar Física. E a proposta era de 
que a Física fosse uma ferramenta de contextualização para o ensino da Matemática. Todas essas percepções do formador, explicitadas ou implícitas nos planos, foram organizadas para a discussão em grupo durante a última etapa.

A última etapa - reflexão e reorganização dos planos - Essa foi a etapa mais enriquecedora e talvez a mais difícil, uma vez que foram partilhados conhecimentos e limitações com toda a turma. Durante o processo de reformulação dos planos todos se expuseram e deram palpites em relação aos planos organizados. A partir do material reunido pelo formador, os licenciandos refletiram sobre os planos e perceberam a necessidade de conhecimentos pedagógicos (procedimentais e atitudinais) e conceituais (científicos) para alcançar o objetivo almejado, um ensino efetivo. Durante as discussões, os licenciandos preocuparam-se em como seria a abordagem do professor em relação à forma de conduzir a aula, de como aprenderiam juntos com seus alunos e como resolveriam os problemas matemáticos que surgiriam a partir das discussões propostas, mas seus planos não expressavam essa preocupação. Os objetivos não estavam relacionados a aprendizagem dos alunos e sim ao ensino. Esse foi o primeiro passo para a conclusão sobre a importância dos conhecimentos para ensinar.

A discussão e reorganização dos planos continuou na perspectiva dialética de complementaridade entre os saberes a ensinar e os saberes para ensinar, entre o ensinar e o aprender em situações contextualizadas que permitem a generalização.

O movimento de transitar entre o saber a ensinar e o saber para ensinar em experiências contextuais, permitiu o exercício de construção de uma identidade no processo de formação desses futuros professores de Matemática e uma clareza para o exame crítico da natureza do processo de ensino aprendizagem. Isso porque, explicitado por eles mesmos, a aprendizagem do aluno tem uma relação direta com o trabalho docente planejado e realizado. A metodologia empregada pelo professor é fator primordial para o êxito no processo de assimilação de conhecimento pelos estudantes.

Ao final da reflexão e do replanejamento (reorganização dos planos), foi perceptível que os futuros professores entenderam a necessidade de saberes que possibilitem novas formas de ensinar e aprender (o saber para ensinar) conceitos físicos e matemáticos (saber a ensinar) inseridos de forma generalizadora no mundo social que vivemos. Os saberes a ensinar de Matemática, por fornecerem ferramentas para descrever fenômenos; os de Física, por apresentar e discutirem situações; e, dialeticamente, nortearem a utilização de ferramentas matemáticas. 


\section{CONCLUSÕES}

O professor, seja de Matemática ou de Física, é sempre um formador, não podendo ser mero reprodutor do conhecimento. Logo, a proposta da elaboração de um plano de aula, sem o rigor exigido na disciplina de Didática, mas criativo e contextualizado, e sua discussão durante uma aula de Física I, permitiu expor aos licenciandos e conscientizá-los de que o ensinar não depende apenas dos conteúdos conceituais a serem "transmitidos", mas também de habilidades, hábitos e atitudes valorativas que envolvam procedimentos relacionados ao fazer profissional.

O pleno conhecimento das ferramentas matemáticas e dos conceitos físicos de Cinemática e Dinâmica possibilitaram a definição do que era necessário conhecer naquele momento, o que poderia ser discutido em sala de aula durante o período e o que poderia ser aprofundado no período subsequente. Dessa forma, essa experiência procurou nortear o ensino de Matemática, a partir das aulas de Física I ministrada na Licenciatura, na busca da amplitude de significação e da articulação dos saberes de forma contextualizada, interdisciplinar e dinâmica.

É indubitável que a satisfação das demandas surgidas durante o processo de reflexão não foi total. E isso, aquém de ser visto de forma negativa, pode ser motivação para a concepção identitária dos futuros professores como agentes ativos de seu processo de formação e desenvolvimento, num procedimento de busca de métodos alternativos para a otimização do processo de ensino aprendizagem, tendo em conta as peculiaridades que caracterizam os conteúdos. A otimização do ensino aprendizagem dos conteúdos matemáticos exige a formação, por parte dos futuros professores, de um pensamento reflexivo e inovador, mediante a seleção de métodos e ferramentas que ofereçam vias para a busca de conhecimentos e permitam o reconhecimento do valor que possuem os saberes docentes (saberes a ensinar e saberes para ensinar) para seu desempenho profissional.

\section{REFERÊNCIAS}

BATISTA, E., MOZOLEVSKI, I. Métodos de Física-Matemática. Universidade Federal de Santa Catarina - Consórcio ReDiSul. Florianópolois, 2010.

CARDIM, Viviane Rocha Costa \& GRANDO, Regina Célia. Saberes sobre a docência na formação inicial de professores de matemática. Educação Matemática Pesquisa, São Paulo, v.13, n.1, pp.1-34, 2011.

FELICETTI, V. L. e MOROSINI, M. C. Do Compromisso ao Comprometimento: o estudante e a aprendizagem. Educar em Revista, n. especial 2, p. 23-44, 2010. Editora UFPR. 
PIETROCOLA, M. A Matemática como Estruturante do Conhecimento Físico. Caderno Catarinense de Ensino de Física, v. 19, n.1: p.89-109, ago. 2002.

PUENTES, R. V.; AQUINO, O. F.; QUILICI NETO, A. Profissionalização dos professores: conhecimentos, saberes e competências necessários à docência. Educar; Curitiba, n. 34, p.169-184, 2009. Disponível em: <http://www.scielo.br/pdf/er/n34/10.pdf>. Acesso em: 2 set. 2014.

SHULMAN, L. Those who understand: knowldege growth in teaching. Educational Research, v. 17, n. 1, p. 4-14, 1986.

TARDIF, M. Saberes docentes e formação profissional. Petrópolis: Vozes, 2002.

VALENTE, Rodrigues. Os saberes para ensinar matemática e a profissionalização do educador matemático. Revista Diálogo Educacional. Curitiba, v. 17, n. 51, p. 207-222, jan./mar. 2017. Acessado em:

https://periodicos.pucpr.br/index.php/dialogoeducacional/article/view/2836/2758 dia $\underline{10 / 09 / 2018 .}$. 